\title{
Knockdown of Dkk-3 decreases cancer cell migration and invasion independently of the Wnt pathways in oral squamous cell carcinoma-derived cells
}

\author{
NAOKI KATASE ${ }^{1}$, MATHIEU LEFEUVRE ${ }^{1}$, HIDETSUGU TSUJIGIWA ${ }^{1}$, MASAE FUJII ${ }^{1}$, SATOSHI ITO ${ }^{1}$, \\ RYO TAMAMURA ${ }^{1}$, ROSARIO RIVERA BUERY ${ }^{1}$, MEHMET GUNDUZ ${ }^{1,2}$ and HITOSHI NAGATSUKA ${ }^{1}$ \\ ${ }^{1}$ Department of Oral Pathology and Medicine, Graduate School of Medicine, Dentistry and \\ Pharmaceutical Sciences, Okayama University, Okayama, Japan; ${ }^{2}$ Department of Otolaryngology \\ Head and Neck Surgery, Faculty of Medicine, Fatih University, Ankara, Turkey
}

Received November 1, 2012; Accepted January 4, 2013

DOI: 10.3892/or.2013.2251

\begin{abstract}
Oral squamous cell carcinoma (OSCC) is thought to arise as the result of cumulative genetic or epigenetic alterations in cancer-associated genes. We focused on the Dickkopf-3 (Dkk-3) gene as a candidate tumor suppressor in OSCC. Dkk-3 is a potential tumor suppressor, and its downregulation has been reported in various types of malignancies. However, our previous data demonstrated that the Dkk-3 protein was dominantly expressed in OSCC tissue, and its expression was correlated with a high incidence of metastasis and with poor prognosis. In order to explain this paradox, we performed functional analyses of the Dkk-3 gene in cancer cell lines. RT-PCR revealed that Dkk-3 mRNA expression was observed in OSCCderived cell lines but not in gastrointestinal or colorectal adenocarcinoma-derived cell lines. The siRNA for Dkk-3 was transfected into Dkk-3-expressing cells, and the changes in cell proliferation, invasion and migration were assessed. The knockdown of Dkk-3 mRNA by siRNA transfection did not affect cell proliferation, but it significantly decreased cell migration and invasion. To further investigate the precise mechanism that contributes to the potential oncogenic function of Dkk-3, the Wnt canonical pathway and non-canonical pathways were assessed. Western blotting demonstrated that the effect of Dkk-3 knockdown on cell migration or invasion was not caused by activation of the Wnt pathways. These data demonstrated that Dkk-3 expression in OSCC was different than that in adenocarcinomas. Dkk-3 may possess an oncogenic function that is independent of Wnt signaling.
\end{abstract}

Correspondence to: Dr Naoki Katase, Department of Oral Pathology and Medicine, Graduate School of Medicine, Dentistry and Pharmaceutical Sciences, Okayama University, 2-5-1 Shikata-cho, Kita-ku, Okayama 700-8525, Japan

E-mail:katase-n@cc.okayama-u.ac.jp

Key words: head and neck cancer, oral cancer, squamous cell carcinoma, Dkk-3, functional analysis, migration, invasion

\section{Introduction}

Oral squamous cell carcinoma (OSCC) accounts for $5 \%$ of all cancers in men and $2 \%$ in women (1). The clinical features of OSCC are quite variable. Some cases show a high aggressive phenotype including perineural invasion and/or the tendency to metastasize to the lymph nodes resulting in clinical differences in cancer management. It is believed that cumulative aberrations in cancer-critical genes contribute to OSCC carcinogenesis, yet the specific genes that play a pivotal role in cancer invasion, metastasis or clinical diverseness remain unidentified. Our research group is focusing on cancer-specific tumor-suppressor genes (TSGs). To date, we have investigated the chromosomal loci that harbor frequent allelic loss in OSCC through loss of heterozygosity $(\mathrm{LOH})$ analysis. Identification of a candidate TSG is based on the concept that frequently and specifically deleted alleles in cancer tissue may conceal important TSGs and we narrowed down a candidate TSG target.

The Dickkopf (Dkk) family includes candidate TSGs that we detected in $\mathrm{LOH}$ analysis $(2,3)$. Among the Dkk family members, Dkk-1, -2 and -4 antagonize Wnt ligands and function as negative regulators of oncogenic Wnt signaling. Although the Wnt inhibitory function of Dkk-3 is still elusive, the prevention of nuclear localization $(4,5)$ and its decreased expression in cancers may signify its possible TSG function. Downregulation of Dkk mRNA has been reported in a wide range of malignancies, and studies have focused on Dkk-3 as a candidate therapeutic target (6-9).

Contradictorily, our previous data suggested an alternative function of Dkk-3 in OSCC. Patients with LOH in the Dkk-3 locus exhibited a prolonged overall survival and a low incident of nodal metastasis (2). The Dkk-3 protein was dominantly expressed in SCC tissue and cell lines, and patients without Dkk-3 protein expression did not undergo metastasis but exhibited prolonged survival (10). Following the various Dkk-3 expression patterns in normal, dysplastic and SCC tissue, Dkk-3 protein expression was found to be increased accompanied by cancer progression (11). All of these findings strongly suggest the oncogenic function of Dkk-3. 
Due to the possible oncogenic function of Dkk-3, in the present study we investigated the mRNA expression of Dkk-3 in OSCC cell lines, and observed the effects of Dkk-3 knockdown by RNA interference on cell proliferation, migration and invasion.

\section{Materials and methods}

Cell lines. A total of 8 cell lines; HSC2, HSC3, HSC4 and Ca9-22 (OSCC), Kato III and AZ521 (gastric adenocarcinoma) and CW-2 and Colo-320 (colorectal adenocarcinoma) were used in the study. Since Dkk-3 mRNA was not detected in gastric and colorectal cancer cells due to $\mathrm{CpG}$ methylation, they were used as negative controls (12). All cell lines were purchased from Riken BRC through the National BioResource Project of the MEXT, Japan. Cell lines were maintained in Dulbecco's modified Eagle's medium (DMEM; Life Technologies, Grand Island, NY, USA) (HCS2, HSC3, HSC4, Ca9-22 and AZ521) or RPMI-1640 (Sigma-Aldrich, St. Louis, MO, USA) (Kato III, CW-2 and Colo-320) supplemented with $10 \%$ fetal bovine serum (FBS, BioWest, Nuaillé, France) and $100 \mathrm{U} / \mathrm{ml}$ and $0.25 \mu \mathrm{g} / \mathrm{ml}$ of penicillin/streptomycin/ amphotericin B (Life Technologies) in a $\mathrm{CO}_{2}$ incubator with an atmosphere of $95 \%$ air plus $5 \% \mathrm{CO}_{2}$ at $37^{\circ} \mathrm{C}$.

Reverse transcription-polymerase chain reaction ( $R T-P C R)$. Total RNA was extracted from the cell culture according to the acid guanidinium thiocyanate-phenol/chloroform method using TRIzol ${ }^{\circledR}$ (Invitrogen, Carlsbad, CA, USA). The final total RNA was dissolved in diethylpyrocarbonate-treated water, and the absorbance at 260 and $280 \mathrm{~nm}$ was measured in a spectrophotometer (DU-640; Beckman Instruments, Fullerton, CA, USA). Complementary DNA (cDNA) was synthesized using the PrimeScript ${ }^{\circledR}$ II 1st Strand cDNA Synthesis kit (Takara, Shiga, Japan). To synthesize cDNA, $1.0 \mu \mathrm{l}$ of oligo dT primer and $1.0 \mu \mathrm{l}$ of dNTP mixture were added to $5 \mu \mathrm{g}$ of total RNA and then incubated in a water bath at $65^{\circ} \mathrm{C}$ for $10 \mathrm{~min}$. Then, 5X PrimeScript ${ }^{\circledR}$ II buffer, $20 \mathrm{U}$ of RNase inhibitor and $200 \mathrm{U}$ of RTase were added and incubated at $42^{\circ} \mathrm{C}$ for $2 \mathrm{~h}$.

Quantitative RT-PCR was performed by adding $50 \mathrm{mM}$ of $\mathrm{MgCl}_{2}$ and $2.5 \mu \mathrm{l}$ of each specific primer to $2 \mu \mathrm{l}$ of the template cDNA reaction mixture to obtain a final concentration of $5 \mu \mathrm{M}$ primer. Subsequently, $1.25 \mathrm{U}$ of Platinum ${ }^{\circledR}$ Taq DNA polymerase (Invitrogen) was added, and the final volume was adjusted to $25 \mu \mathrm{l}$. PCR for Dkk-3 was carried out using the following primers (12): 5'-CTG GGA GCT AGA GCC TGA TG-3' (forward) and 5'-TCA TAC TCA TCG GGG ACC TC-3' (reverse) for 35 cycles at $94^{\circ} \mathrm{C}$ for $30 \mathrm{sec}, 58^{\circ} \mathrm{C}$ for $30 \mathrm{sec}$ and $72^{\circ} \mathrm{C}$ for $30 \mathrm{sec}$. For normalization, PCR for human GAPDH was performed using the Human GAPDH Primer Set kit (Maxim Biotech Inc., South San Francisco, CA, USA).

PCR products were confirmed by electrophoresis on a $1.5 \%$ agarose gel, and stained with ethidium bromide. The target amplification products were compared under conditions where PCR amplification had not reached saturation. The band density was quantitatively analyzed using a densitometer and the ImageJ program (http://rsb.info.nih.gov/ij/).

Small interference RNA (siRNA). Small interference RNA (siRNA) for Dkk-3 and the negative control non-targeting siRNA were purchased from Thermo Scientific Dharmacon (Waltham, MA, USA). The targeting sequence of Dkk-3 siRNA \#1 (J-018352-11-0005, ON-TARGETplus siRNA, human Dkk-3) and Dkk-3 siRNA \#2 (J-018352-12-0005, ON-TARGETplus siRNA, human Dkk-3) were AUCCAUGUGCACCGAGAAA and CCAGAGAGGUCCCCGAUGA, respectively. As the negative control (siRNA NC), D-001810-01-15, ON-TARGETplus non-targeting siRNA \#1 was used. The siRNA was suspended in $100 \mu \mathrm{M}$ of $1 \mathrm{X}$ siRNA buffer and diluted with $5 \mathrm{X}$ siRNA buffer (Thermo Scientific Dharmacon) in order to prepare $20 \mu \mathrm{M}$ siRNA solutions.

siRNA transfection was performed using Lipofectamine ${ }^{\circledR}$ RNAiMAX (Invitrogen) according to the manufacturer's instructions. Briefly, Ca9-22 or HSC4 cells were plated at $30-50 \%$ confluence in 100-mm cell culture dishes in DMEM without antibiotics. The following day, $600 \mathrm{pmol}$ of siRNA in $1 \mathrm{ml}$ Opti-MEM ${ }^{\circledR}$ I reduced serum medium (Invitrogen) and $35 \mu$ of Lipofectamine ${ }^{\circledR}$ RNAiMAX in 1 ml Opti-MEM ${ }^{\circledR}$ were mixed. After incubation for $20 \mathrm{~min}$, the mixture was added to the cultured cells. The cells were maintained in an incubator for 2 days. The knockdown of Dkk-3 mRNA expression was confirmed by RT-PCR. In order to confirm the effect of the knockdown gene, the data were collected 2 days and 1 week following siRNA transfection.

Cell proliferation assay. In order to assess the effect of Dkk-3 knockdown on cell proliferation, an MTT assay was performed using TACS ${ }^{\circledR}$ Cell Proliferation Assays (Trevigen, St. Gaithersburg, MD, USA). Ca9-22 or HSC4, cells with/without siRNA transfection, were suspended $\left(1.0 \times 10^{3}\right.$ cells $)$ in $100 \mu 1$ of medium supplemented with $10 \%$ FBS, plated in 96-well microplates and cultured for $24 \mathrm{~h}$. MTT (10 $\mu \mathrm{l})$ was added and incubation was carried out to form formazan crystals. After $4 \mathrm{~h}$ of incubation, $100 \mu \mathrm{l}$ of each detergent agent was added and the absorbance was measured at $570 \mathrm{~nm}$. Data were acquired on day 1, 3 and 5 .

Migration assay. The cell migration assay was performed using an Ibidi Culture-insert (Ibidi GmbH, Munich, Germany) following the manufacturer's protocol. Briefly, Ca9-22 or HSC4 cells were cultured, and siRNA transfection was performed. Then, the cells were harvested using Trypsin/EDTA and resuspended in DMEM with $10 \%$ FBS $\left(\sim 7.0 \times 10^{5}\right.$ cells $\left./ \mathrm{ml}\right)$. The cell suspension $(70 \mu \mathrm{l})$ was transferred to the well of the Culture-insert on a 35-mm dish and then removed using sterilized tweezers after $24 \mathrm{~h}$ of incubation in a $5 \% \mathrm{CO}_{2}$ incubator. Cell migration was observed over time by adding $2 \mathrm{ml}$ DMEM with $10 \%$ FBS. The increase in the area after $12 \mathrm{~h}$ was measured using ImageJ.

Matrigel invasion assay. The BD BioCoat ${ }^{\mathrm{TM}}$ Growth Factor Reduced Matrigel ${ }^{\mathrm{TM}}$ Invasion Chamber System (BectonDickinson, Franklin Lakes, NJ, USA) was used for the invasion assay according to the manufacturer's instructions and based on a previous report (13). Briefly, siRNA transfection of the Ca9-22 or HSC4 cells was performed as previously described. The cells were harvested using Trypsin/EDTA and resuspended in serum-free DMEM $\left(\sim 2.5 \times 10^{5}\right.$ cells $/ 0.5 \mathrm{ml} /$ well $)$, and seeded into a 24-well BD Matrigel ${ }^{\mathrm{TM}}$ insert and control insert $\left(8-\mu \mathrm{m}\right.$ pore size). Inserts were placed in Falcon ${ }^{\mathrm{TM}}$ Companion 


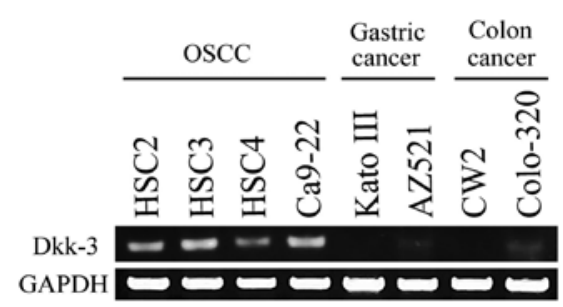

Figure 1. RT-PCR revealed that Dkk-3 mRNA expression was observed only in OSCC-derived cell lines, while gastric cancer cell lines and colorectal cell lines were negative for Dkk-3.

Plates containing DMEM with $10 \%$ FBS and incubated for $24 \mathrm{~h}$. After cell invasion, the cells were removed from the top chamber using cotton swabs. In order to count the number of cells invading or migrating to the other side of the membrane, the membranes were fixed and stained with Diff-Quik Stain ${ }^{\mathrm{TM}}$ (Lab Aids Pty Ltd., North Narrabeen, Australia) and mounted on a glass slide. The slide was scanned with Virtual Slide System VS110 (Olympus, Tokyo, Japan), and cells were counted using the ImageJ program. Cell invasion was compared with the invasion index and calculated according to the manufacturer's instructions.

Western blotting. In order to confirm a decrease in Dkk-3 and how long it was maintained, western blotting was performed. The data were acquired in the Ca9-22 cells following 1 week with or without siRNA transfection. The cell extracts were boiled for $5 \mathrm{~min}$ in sodium dodecyl sulfate (SDS) gel-loading buffer (0.1 M Tris-HCl, pH 6.8, 20\% glycerol, 2.5\% SDS, $0.05 \%$ bromophenol blue and $5 \% \beta$-mercaptoethanol). An equal amount of each protein sample was then loaded and separated onto $12.5 \%$ SDS-polyacrylamide gels and blotted onto polyvinylidene difluoride (PVDF) membranes. After blocking the non-specific binding by soaking the PVDF membranes in 5\% skim milk, proteins were detected using anti-Dkk-3 (Sigma-Aldrich), $\beta$-catenin-phosphoS37 (Abcam, Cambridge, MA, USA), non-phospho(active) $\beta$-catenin (Ser33/37/Thr41) (Cell Signaling Technology, Danvers, MA, USA), RhoA, Cdc42 and Rac1 (Abcam). Anti-tubulin (SigmaAldrich) was used for normalization. Proteins were visualized using the ECL Prime Western Blotting Detection System (GE Healthcare Life Sciences, Pittsburgh, PA, USA).

Statistical analysis. Significant differences between the control and the siRNA groups were determined by the twotailed multiple Student's t-test with Bonferoni correction following the Dunnett's test. All computations were performed using PASW Statistics 18 (SPSS Inc., Chicago, IL, USA). A $\mathrm{P}$-value $<0.05$ was considered to indicate a statistically significant result.

\section{Results}

Dkk-3 mRNA expression. RT-PCR demonstrated Dkk-3 mRNA expression in all OSCC cell lines. However, expression in gastric cancer cell lines or colon cancer cell lines were lost or ignorable (Fig. 1). Among the OSCC cell lines, Dkk-3 mRNA expression was comparatively high in the Ca9-22 cells
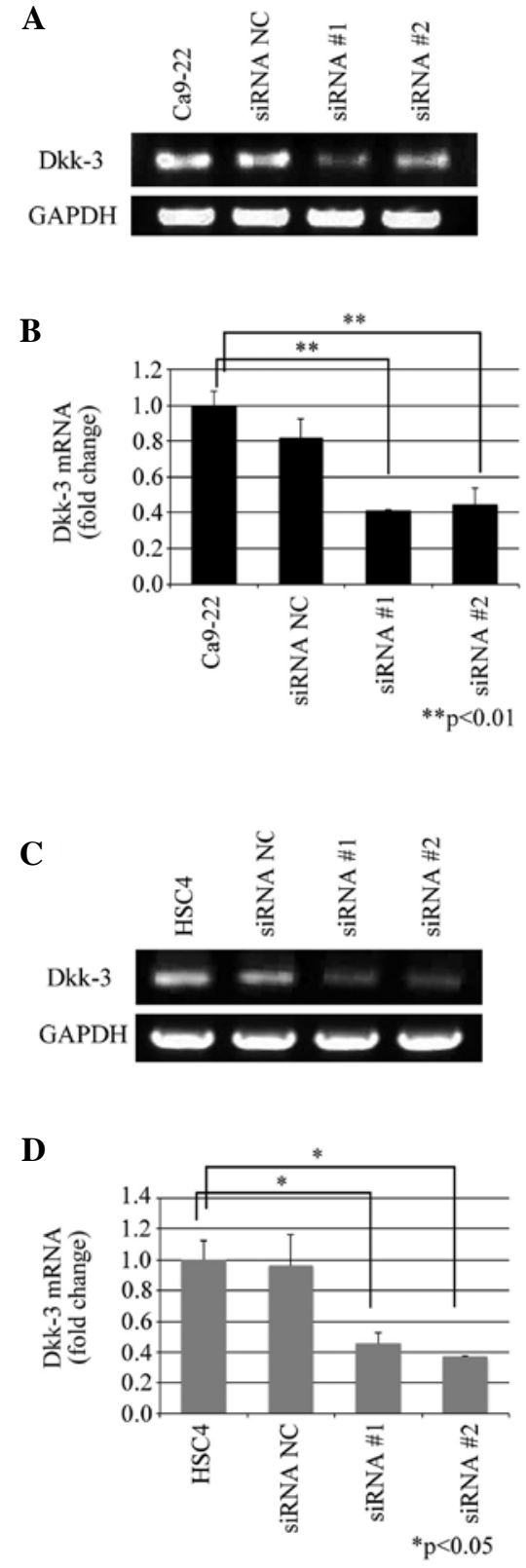

Figure 2. siRNA transfection decreased Dkk-3 mRNA expression in (A) Ca9-22 and (C) HSC4 cells. (B and D) Quantitative analysis showed changes in mRNA expression of Dkk-3. Both siRNA \#1 and \#2 significantly decreased mRNA expression. ${ }^{* *} \mathrm{P}<0.01,{ }^{*} \mathrm{P}<0.05$.

and that of HSC4 was comparatively low. In the following experiments, Ca9-22 and HSC4 cells were used in order to investigate the effects of Dkk-3 knockdown by siRNA on cell proliferation, migration and cell invasion.

Knockdown of Dkk-3 mRNA expression by siRNA. Knockdown of Dkk-3 mRNA expression was performed by RNA interference. Both of the siRNAs for Dkk-3 (siRNA \#1 and siRNA \#2) decreased Dkk-3 expression in the Ca9-22 and HSC4 cells whereas control siRNA (siRNA NC) did not significantly impact the RNA expression (Fig. 2A and C). Dkk-3 expressions in Ca9-22 cells was attenuated by $18.9 \%$ (siRNA NC, $\mathrm{P}=0.175$ ), 59.1\% (siRNA \#1, $\mathrm{P}=0.04$ ) and 55.5\% (siRNA \#2, $\mathrm{P}=0.005$ ), respectively (Fig. $2 \mathrm{~B}$ ). The attenuation in Dkk-3 expression in HSC4 cells was $3.8 \%$ (siRNA NC, $\mathrm{P}=0.979$ ), 


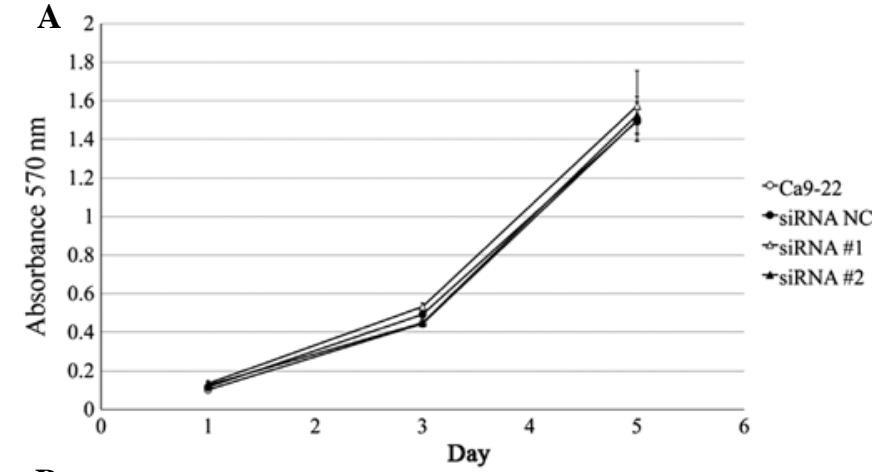

B

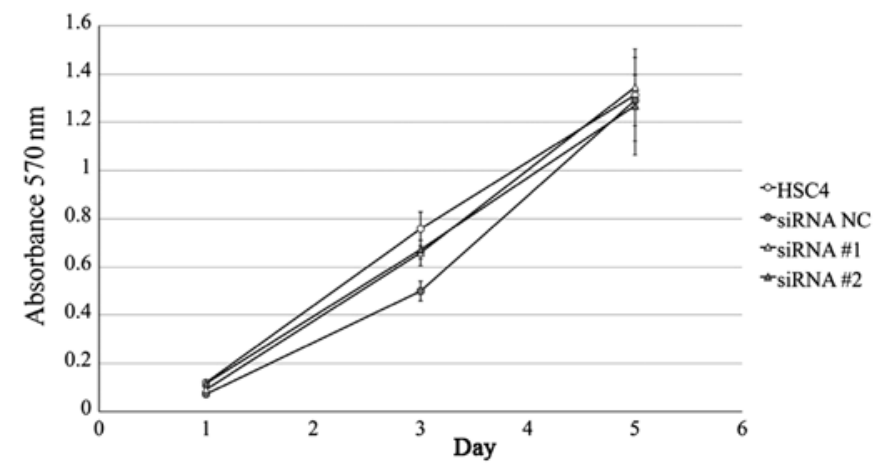

Figure 3. MTT assay. No significant difference in the cell prolferation among the parental and siRNA groups was obtained in (A) Ca9-22 and (B) HSC4 cells.

$54.2 \%$ (siRNA \#1, $\mathrm{P}=0.028$ ) and $64.3 \%$ (siRNA \#2, $\mathrm{P}=0.016$ ), respectively (Fig. 2D).

MTT assay. To determine the effect of Dkk-3 knockdown on cell proliferation in the OSCC cell lines, an MTT cell proliferation assay was carried out. Cell proliferation was assessed 1, 3 and 5 days following siRNA transfection. No significant differences among the group were obtained in the $\mathrm{Ca} 9-22$ cell line (Fig. 3A). Although transfection with siRNA NC tended to show decreased proliferation in HSC4 cells, no significant difference was obtained (Fig. 3B).

Migration assay. The effect of Dkk-3 knockdown on cell migration is shown in Fig. 4. Changes in cell migration were measured as the area recovered after the 12-h migration and was expressed as the relative change in area. Notably, Dkk-3 knockdown significantly decreased cell migration both in the Ca9-22 and HSC4 cells (Fig. 4A and C). Regarding the Ca9-22 cells, the mean area recovery ratio was $99.84 \pm 0.42$ (control), 95.34 \pm 8.28 (siRNA NC), $92.42 \pm 9.83$ (siRNA \#1) and $73.03 \pm 6.56 \%$ (siRNA \#2), respectively (Fig. 4B). The mean area recovery ratio in HSC4 cells was $87.76 \pm 16.50$ (control), $84.23 \pm 11.42$ (siRNA NC), 89.15 \pm 6.82 (siRNA \#1) and $63.05 \pm 14.06 \%$ (siRNA \#2), respectively (Fig. 4D). Statistical analysis revealed that Dkk-3 knockdown by siRNA \#2 significantly decreased cell migration both in the Ca9-22 and HCS4 cells $(\mathrm{P}<0.001$ and $\mathrm{P}=0.033$, respectively).

Matrigel invasion assay. In order to investigate the effect of Dkk-3 knockdown on the invasive ability, a Matrigel invasion assay was performed. Invasive ability was assessed according to the manufacturer's protocol. Initially, the percentage of
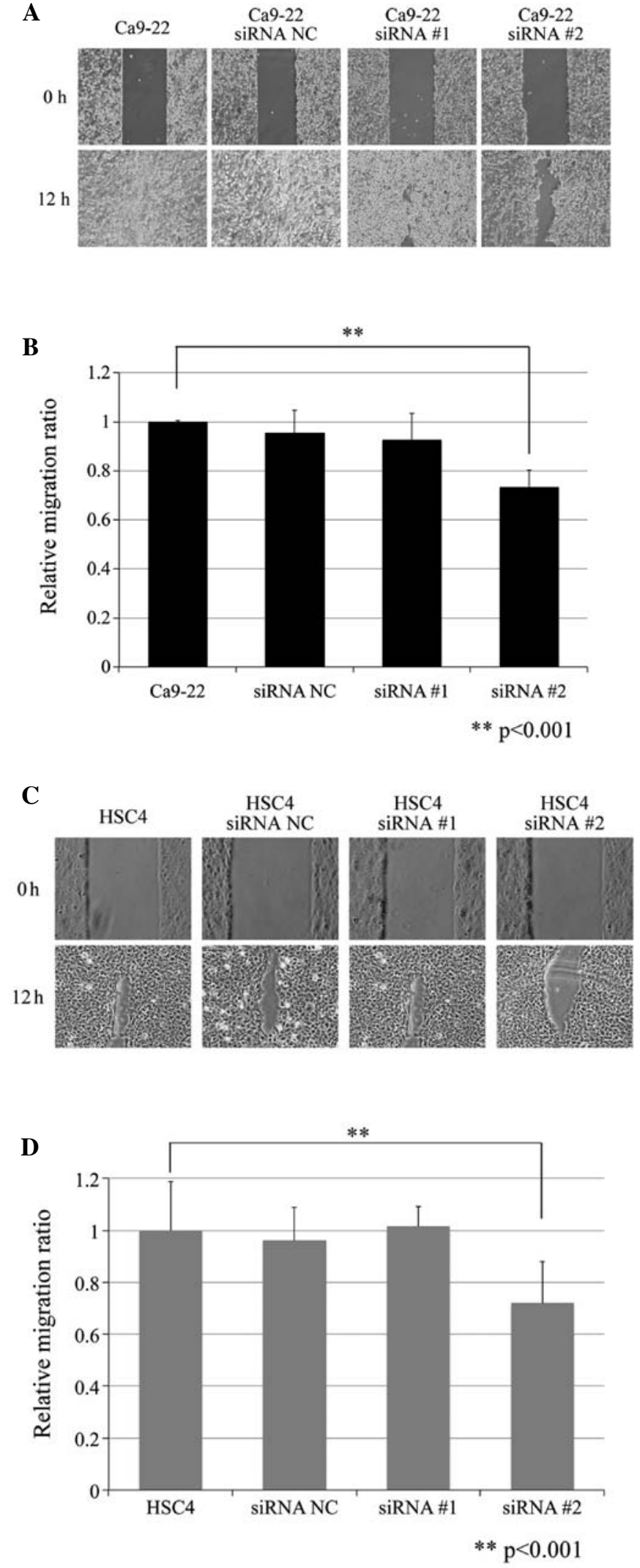

Figure 4. Migration assay. (A) Results revealed that knockdown of Dkk-3 decreased cell migration in Ca9-22 cells. (B) In particular, siRNA \#2 significantly decreased cell migration. (C and D) In the HSC 4 cells, although siRNA \#1 did not affect cell migration, \#2 significantly decreased cell migration.

invasion was calculated by dividing the number of cells that invaded through the Matrigel insert by the number of cells 
A

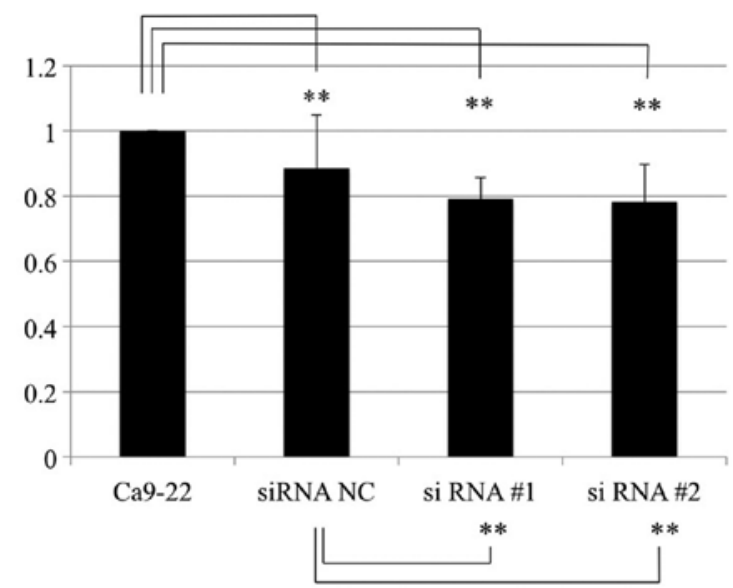

B

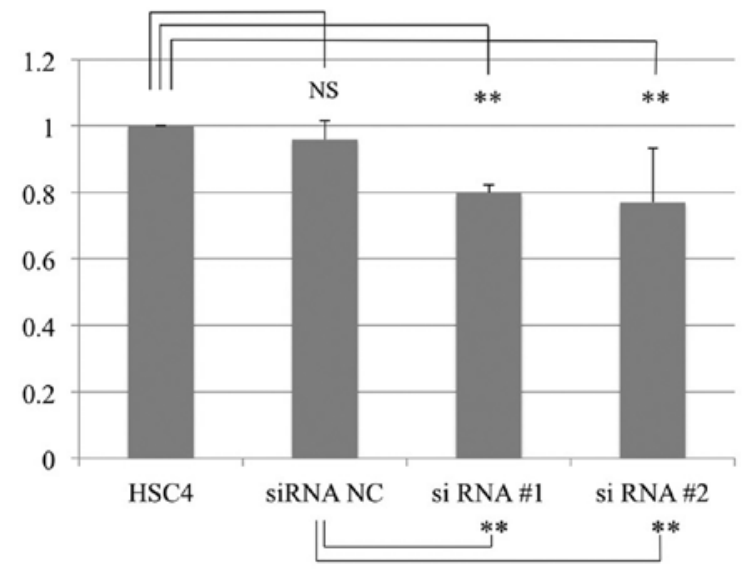

Figure 5. Matrigel invasion assay demonstrated that Dkk-3 knockdown significantly decreased cell invasion. ${ }^{* *} \mathrm{P}<0.001$; NS, not significant.

that migrated through the control insert. The relative invasion index was then calculated by dividing the percentage of invasion of the siRNA group with that of the control cells (Fig. 5). The relative invasion indices for the Ca9-22 cells were $0.885 \pm 0.162$ (siRNA NC, P=0.004), 0.793 \pm 0.064 (siRNA \#1, $\mathrm{P}<0.001$ ) and $0.783 \pm 0.114$ (siRNA \#2, $\mathrm{P}<0.001$ ), respectively. Relative indices for Ca9-22 NC cells were $0.872 \pm 0.084$ (siRNA \#1, P<0.001) and 0.896 \pm 0.042 (siRNA \#2, $\mathrm{P}<0.001$ ), respectively.

The relative invasion indices for $\mathrm{HSC} 4$ cells were $0.958 \pm 0.057$ (siRNA NC, $\mathrm{P}=0.259$ ), $0.798 \pm 0.023$ (siRNA \#1, $\mathrm{P}<0.001$ ) and $0.770 \pm 0.163$ (siRNA \#2, $\mathrm{P}<0.001$ ), respectively. The relative invasion indices for the HSC4 NC cells were $0.841 \pm 0.048$ (siRNA \#1, $\mathrm{P}<0.001$ ) and $0.816 \pm 0.137$ (siRNA \#2, $\mathrm{P}<0.001$ ), respectively. The relative invasion indices indicated that siRNA significantly decreased cell invasion.

Western blotting. Western blotting revealed that knockdown of Dkk-3 mRNA resulted in protein reduction, even 1 week after siRNA transfection (Fig. 6). The expression profile of the proteins that are associated with the Wnt canonical ( $\beta$-catenin and active $\beta$-catenin) or the non-canonical pathway (RhoA, cdc42 and Rac1) were determined. Dkk-3 knockdown did not affect the expression of any protein in either the Wnt canonical (Wnt// $\beta$-catenin) pathway or noncanonical pathway.

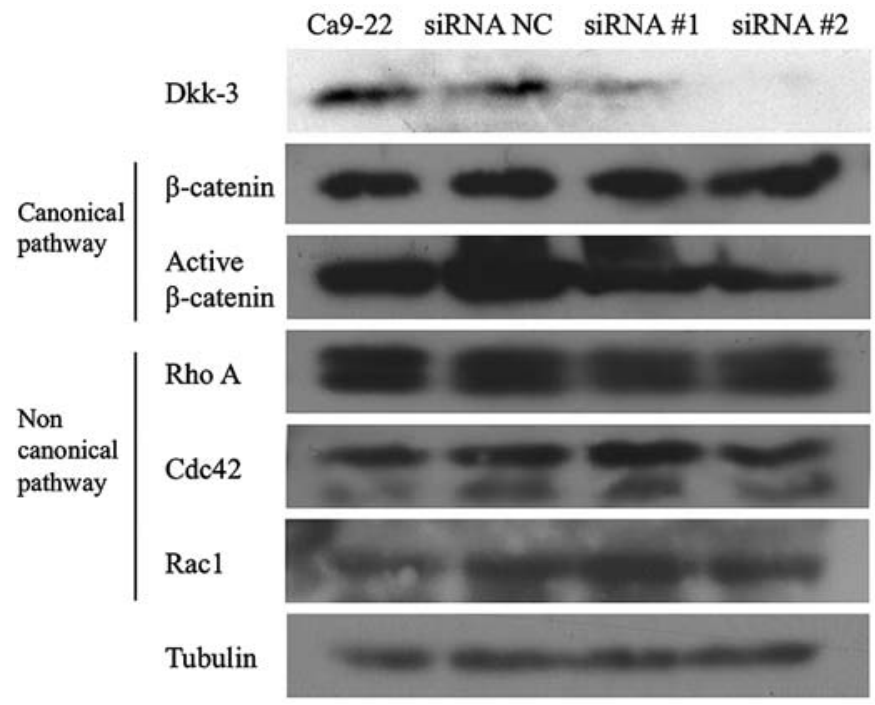

Figure 6. Western blot analysis of cell signaling molecules associated with the Wnt canonical and non-canonical pathways. Dkk-3 knockdown resulted in Dkk-3 protein reduction. Dkk-3 knockdown did not affect $\beta$-catenin or active $\beta$-catenin levels. Molecules involved in the non-canonical pathway such as small GTPase molecules, RhoA, Cdc42 or Rac1 showed no differences regardless of Dkk-3 expression.

\section{Discussion}

OSCC is thought to arise as a result of cumulative genetic aberrations of TSGs or signals that control cell proliferation, migration and invasion. Wnt signaling and its regulators are one of the important pathways often dysregulated in cancer. The Dkk family is one of the Wnt regulators that antagonizes Wnt ligands together with the Wnt inhibitory factor (WIF) and secreted frizzled related proteins (sFRPs). Although the Wnt inhibitory activity of Dkk-3 is still questionable, its downregulation by $\mathrm{CpG}$ methylation was reported in various cancer types including gastrointestinal tumors (14), hepatocellular carcinoma (15), breast cancer (16), ovarian cancer (17), cervical cancer (18) and glioma (19). Hence, various studies have regarded Dkk-3 as a putative Wnt signaling inhibitor. In oral cancer, Pannone et al (20) reported that Wnt inhibitors including WIF-1, sFRPs and Dkk-3 are epigenetically inactivated. In this regard, Dkk-3 seems to be a TSG in which its downregulation is very common regardless of tissue origin.

Nevertheless, our previous studies showed that the Dkk family is a novel and independent candidate tumor suppressor in OSCC by genome-wide $\mathrm{LOH}$ analysis $(2,3)$. An allele in the Dkk-3 locus is frequently deleted in HNSCC suggesting that Dkk-3 functions as a TSG. However, survival analysis revealed that Dkk-3 LOH (+) patients exhibited an increased diseasefree survival and significantly prolonged overall survival. LOH analysis can simply detect allelic loss in particular loci or genes including true TSGs and genes that have been deleted due to carcinogenesis. Furthermore, Dkk-3 protein expression was found to be increased in dysplasia and further in SCC. In addition, Dkk-3 (-) patients exhibited a significantly prolonged disease-free survival and absence of metastasis $(10,11)$. Taken together, we hypothesized that Dkk-3 may not only be a TSG but may also be an oncogene. In order to verify this hypothesis, we performed functional analyses of Dkk-3 by RNA 
interference and determined its effect on the Wnt canonical and non-canonical pathways.

In the present research, Dkk-3 was detected only in the OSCC-derived cell lines but not in the gastrointestinal or colorectal adenocarcinoma-derived cells. Transfection of siRNA in OSCC cells lines decreased Dkk-3 expression, which did not affect cell proliferation but did decreased cellular migration. The present study strongly supports our hypothesis that Dkk-3 possesses potential oncogenic function. Furthermore, this may explain our previous data that patients lacking Dkk-3 protein expression showed significantly longer disease-free and metastasis-free survival. Moreover, because OSCC cell lines express Dkk-3 mRNA, the loss of Dkk-3 mRNA expression is not a part of the carcinogenic process in oral epithelium.

The mechanism by which Dkk-3 exerts oncogenic function remains unknown. We hypothesized the Wnt canonical and non-canonical pathways as probable targets. Firstly, the canonical Wnt pathway ( $\beta$-catenin pathway) is a major signaling pathway that participates in carcinogenesis. The present data revealed that both $\beta$-catenin and active $\beta$-catenin were equally observed regardless of Dkk-3 protein expression status, implying that Dkk-3 may not function as regulator of Wnt $/ \beta$-catenin signaling in OSCC and that aberrant $\beta$-catenin expression is independent of Dkk-3 expression.

$\beta$-catenin acts not only as a transcriptional activator that mediates Wnt signaling but also as a structural protein in cell adhesion junctions $(21,22)$. An in vitro study using an OSCC cell line demonstrated that aberrant $\beta$-catenin accumulation in the cytoplasm induces TCF/Lef-mediated transcriptional activity, increased matrix metalloproteinase (MMP)-7 expression and induced epithelial mesenchymal transition (EMT), resulting in higher invasion/migration capacities (23). The function of nuclear $\beta$-catenin (active $\beta$-catenin) in the canonical pathway is also controversial. Tenbaum et al (24) reported that $\beta$-catenin provides resistance to AKT inhibitors and that apoptosis-related molecule FOXO3a changes its function promoting metastasis when it co-localizes with $\beta$-catenin in colon cancer cells. Therefore, it is likely that Dkk-3 accumulated in cytoplasm may act differently from secreted Dkk-3 and that the oncogenic function of Dkk-3 is closely related to aberrantly accumulated $\beta$-catenin.

Secondly, recent reports have indicated that the noncanonical Wnt pathway may play an important role in cancer invasion. Particularly, the Rho family of small GTPases acting downstream of Wnt receptor function in cell migration (25). The Wnt/Rho kinase pathway is related to stress fiber formation, and the Wnt/Cdc42/Rac1 pathway is associated in lamellipodia formation in cell migration. The Rho family of GTPases, RhoA and Rho family members $\mathrm{Cdc} 42$ were reported to regulate E-cadherin-dependent cellular adhesion and may interact with $\beta$-catenin (23). The present data showed that Dkk-3 knockdown affected neither the Wnt/Rho kinase pathway nor Wnt/Cdc42/ Rac1 expression, indicating no evident linkage between Dkk-3 and the Wnt non-canonical pathway.

On the other hand, Dkk-3 seems to possess various functions. Dkk-3, otherwise known as REIC (reduced expression in cancer), implies a tumor-suppressive function (26). Dkk-3 is now the clinical target of gene therapy in pancreatic (7), prostate $(27,28)$, gastric scirrhous (8), breast (29) and testicular cancer (30). Yet, these reports conclude that the tumor inhibitory function of Dkk-3 is caused by apoptosis induction due to endoplasmic reticulum stress or JNK phosphorylation and not by its primary tumor suppressor function. The possibility that Dkk-3 mutation may exhibit a dominant-negative function warrants discussion. To date, there is no report on Dkk-3 genetic mutations in malignancies, although many reports suggest epigenetic changes in Dkk-3.

Although the present results further support our previous data that patients with Dkk-3 expression demonstrated a shorter disease-free and metastasis-free survival, the results provide another point of interest in the functional role of Dkk-3 in OSCC. In conclusion, increased invasion and migration by Dkk-3 knockdown may be driven by a mechanism other than Wnt/ $\beta$-catenin signaling, yet Dkk-3 may be a clinical target for prevention of OSCC invasion.

\section{Acknowledgements}

This study was partially supported by a Grant-in-Aid for Scientific Research from the Ministry of Education, Culture, Sports, Science and Technology, Japan to N.K. (22791766), H.T. (22791977), R.T. (24592766) and H.N. (24659891).

\section{References}

1. Johnson N, Franceschi S, Ferlay J, Ramadas K, Schmid S, MacDonald DG Bouquet JE and Slootweg PJ: Squamous cell carcinoma. In: WHO Classification of Tumours. Pathology and Genetics of Head and Neck Tumours. Barnes L, Eveson JW, Reichart P and Sideransky D (eds). IARC Press, Lyon, pp168-175, 2005.

2. Katase N, Gunduz M, Beder L, Gunduz E, Lefeuvre M, Hatipoglu OF, Borkosky SS, Tamamura R, Tominaga S, Yamanaka N, Shimizu K, Nagai N and Nagatsuka H: Deletion at Dickkopf (dkk)-3 locus (11p15.2) is related with lower lymph node metastasis and better prognosis in head and neck squamous cell carcinomas. Oncol Res 17: 273-282, 2008.

3. Katase N, Gunduz M, Beder LB, Gunduz E, Al Sheikh Ali M, Tamamura R, Yaykasli KO, Yamanaka N, Shimizu K and Nagatsuka H: Frequent allelic loss of Dkk-1 locus (10q11.2) is related with low distant metastasis and better prognosis in head and neck squamous cell carcinomas. Cancer Invest 28: 103-110, 2010.

4. Veeck J and Dahl E: Targeting the Wnt pathway in cancer: the emerging role of Dickkopf-3. Biochim Biophys Acta 1825: 18-28, 2012.

5. Hoang BH, Kubo T, Healey JH, Yang R, Nathan SS, Kolb EA, Mazza B, Meyers PA and Gorlick R: Dickkopf 3 inhibits invasion and motility of Saos-2 osteosarcoma cells by modulating the Wnt-beta-catenin pathway. Cancer Res 64: 2734-2739, 2004.

6. Gu YM, Ma YH, Zhao WG and Chen J: Dickkopf3 overexpression inhibits pancreatic cancer cell growth in vitro. World J Gastroenterol 17: 3810-3817, 2011.

7. Abarzua F, Sakaguchi M, Takaishi M, Nasu Y, Kurose K, Ebara S Miyazaki M, Namba M, Kumon H and Huh NH: Adenovirusmediated overexpression of REIC/Dkk-3 selectively induces apoptosis in human prostate cancer cells through activation of c-Jun-NH2-kinase. Cancer Res 65: 9617-9622, 2005.

8. Than SS, Kataoka K, Sakaguchi M, Murata H, Abarzua F, Taketa C, Du G, Yashiro M, Yanagihara K, Nasu Y, Kumon H and Huh NH: Intraperitoneal administration of an adenovirus vector carrying REIC/Dkk-3 suppresses peritoneal dissemination of scirrhous gastric carcinoma. Oncol Rep 25: 989-995, 2011.

9. Sakaguchi M, Kataoka K, Abarzua F, Tanimoto R, Watanabe M, Murata H, ThanSS, Kurose K, Kashiwakura Y, Ochiai K, Nasu Y, Kumon H and Huh NH: Overexpression of REIC/Dkk-3 in normal fibroblasts suppresses tumor growth via induction of interleukin-7. J Biol Chem 284: 14236-14244, 2009. 
10. Katase N, Lefeuvre M, Gunduz M, Gunduz E, Beder LB, Grenman R, Fujii M, Tamamura R, Tsujigiwa $H$ and Nagatsuka H: Absence of Dickkopf (Dkk)-3 protein expression is correlated with longer disease-free survival and lower incidence of metastasis in head and neck squamous cell carcinoma. Oncol Lett 3: 273-280, 2012.

11. Fujii M, Katase N, Lefeuvre M, Gunduz M, Buery RR, Tamamura R, Tsujigiwa $\mathrm{H}$ and Nagatsuka H: Dickkopf (Dkk)-3 and $\beta$-catenin expressions increased in the transition from normal oral mucosal to oral squamous cell carcinoma. J Mol Histol 42: 499-504, 2011

12. Maehata T, Taniguchi H, Yamamoto H, Nosho K, Adachi Y, Miyamoto N, Miyamoto C, Akutsu N, Yamaoka S and Itoh F: Transcriptional silencing of Dickkopf gene family by $\mathrm{CpG}$ island hypermethylation in human gastrointestinal cancer. World J Gastroenterol 14: 2702-2714, 2008.

13. Hughes L, Malone C, Chumsri S, Burger AM and McDonnell S: Characterisation of breast cancer cell lines and establishment of a novel isogenic subclone to study migration, invasion and tumourigenicity. Clin Exp Metastasis 25: 549-557, 2008.

14. Sato H, Suzuki H, Toyota M, Nojima M, Maruyama R, Sasaki S, Takagi H, Sogabe Y, Sasaki Y, Idogawa M, Sonoda T, Mori M, Imai K, Tokino $\mathrm{T}$ and Shinomura Y: Frequent epigenetic inactivation of DICKKOPF family genes in human gastrointestinal tumors. Carcinogenesis 28: 2459-2566, 2007.

15. Ding Z, Qian YB, Zhu LX and Xiong QR: Promoter methylation and mRNA expression of DKK-3 and WIF-1 in hepatocellular carcinoma. World J Gastroenterol 15: 2595-2601, 2009.

16. Veeck J, Wild PJ, Fuchs T, Schüffler PJ, Hartmann A, Knüchel R and Dahl E: Prognostic relevance of Wnt-inhibitory factor-1 (WIF1) and Dickkopf-3 (DKK3) promoter methylation in human breast cancer. BMC Cancer 9: 217, 2009.

17. You A, Fokas E, Wang LF, He H, Kleb B, Niederacher D, Engenhart-Cabillic R and An HX: Expression of the Wnt antagonist DKK3 is frequently suppressed in sporadic epithelial ovarian cancer. J Cancer Res Clin Oncol 137: 621-627, 2011.

18. van der Meide WF, Snellenberg S, Meijer CJ, Baalbergen A, Helmerhorst TJ, vanderSluis WB, Snijders PJ and Steenbergen RD: Promoter methylation analysis of WNT/ $\beta$-catenin signaling pathway regulators to detect adenocarcinoma or its precursor lesion of the cervix. Gynecol Oncol 123: 116-122, 2011

19. Götze S, Wolter M, Reifenberger G, Müller O and Sievers S: Frequent promoter hypermethylation of Wnt pathway inhibitor genes in malignant astrocytic gliomas. Int J Cancer 126: 2584-2593, 2010.

20. Pannone G, Bufo P, Santoro A, Franco R, Aquino G, Longo F, Botti G, Serpico R, Cafarelli B, Abbruzzese A, Caraglia M, Papagerakis S and Lo Muzio L: WNT pathway in oral cancer: epigenetic inactivation of WNT-inhibitors. Oncol Rep 24: $1035-1041,2010$
21. Laxmidevi LB, Angadi PV, Pillai RK and Chandreshekar C: Aberrant $\beta$-catenin expression in the histologic differentiation of oral squamous cell carcinoma and verrucous carcinoma: an immunohistochemical study. J Oral Sci 52: 633-640, 2010.

22. Yu Z, Weinberger PM, Provost E, Haffty BG, Sasaki C, Joe J, Camp RL, Rimm DL and Psyrri A: beta-Catenin functions mainly as an adhesion molecule in patients with squamous cell cancer of the head and neck. Clin Cancer Res 11: 2471-2477, 2005.

23. Iwai S, Yonekawa A, Harada C, Hamada M, Katagiri W, Nakazawa $M$ and Yura Y: Involvement of the Wnt- $\beta$-catenin pathway in invasion and migration of oral squamous carcinoma cells. Int J Oncol 37: 1095-1103, 2010.

24. Tenbaum SP, Ordóñez-Morán P, Puig I, Chicote I, Arqués O, Landolfi S, Fernández Y, Herance JR, Gispert JD, Mendizabal L, Aguilar S, Ramón y Cajal S, Schwartz S Jr, Vivancos A, Espín E, Rojas S, Baselga J, Tabernero J, Muñoz A and Palmer HG: $\beta$-catenin confers resistance to $\mathrm{PI} 3 \mathrm{~K}$ and AKT inhibitors and subverts FOXO3a to promote metastasis in colon cancer. Nat Med 18: 892-901, 2012.

25. Ishida-Takagishi M, Enomoto A, Asai N, Ushida K, Watanabe T, Hashimoto T, Kato T, Weng L, Matsumoto S, Asai M, Murakumo Y, Kaibuchi K, Kikuchi A and Takahashi M: The Dishevelled-associating protein Daple controls the non-canonical Wnt/Rac pathway and cell motility. Nat Commun 3: 859, 2012.

26. Tsuji T, Miyazaki M, Sakaguchi M, Inoue $\mathrm{Y}$ and Namba M: A REIC gene shows down-regulation in human immortalized cells and human tumor-derived cell lines. Biochem Biophys Res Commun 268: 20-24, 2000.

27. Kawauchi K, Watanabe M, Kaku H, Huang P, Sasaki K, Sakaguchi M, Ochiai K, Huh NH, Nasu Y and Kumon H: Preclinical safety and efficacy of in situ REIC/Dkk-3 gene therapy for prostate cancer. Acta Med Okayama 66: 7-16, 2012.

28. Edamura K, Nasu Y, Takaishi M, Kobayashi T, Abarzua F, Sakaguchi M, Kashiwakura Y, Ebara S, Saika T, Watanabe M, Huh NH and Kumon H: Adenovirus-mediated REIC/Dkk-3 gene transfer inhibits tumor growth and metastasis in an orthotopic prostate cancer model. Cancer Gene Ther 14: 765-772, 2007.

29. Kawasaki K, Watanabe M, Sakaguchi M, Ogasawara Y, Ochiai K, Nasu Y, Doihara H, Kashiwakura Y, Huh NH, Kumon $\mathrm{H}$ and Date H: REIC/Dkk-3 overexpression downregulates P-glycoprotein in multidrug-resistant CF7/ADR cells and induces apoptosis in breast cancer. Cancer Gene Ther 16: 65-72, 2009.

30. Tanimoto R, Abarzua F, Sakaguchi M, Takaishi M, Nasu Y, Kumon H and Nuh NH: REIC/Dkk-3 as a potential gene therapeutic agent against human testicular cancer. Int J Mol Med 19: 363-368, 2007. 